\title{
Manfaat Ekonomi Pengrajin Anyaman Di Kampung Arborek Kecamatan Meosmansar Kabupaten Raja Ampat
}

Serita Victoriana Umalan a,1, I Putu Anoma,2

${ }^{1}$ seritaumalan@gmail.com, 2putuanom@unud.ac.id

a Program Studi S1 Destinasi Pariwisata, Fakultas Pariwisata,Universitas Udayana, Jl. Dr. R. Goris, Denpasar, Bali 80232 Indonesia

\section{Abstract}

The purpose of this research is to know the benefits of tourism coast economy are felt directly by the local people in Meosmansar Subdistrict, Raja Ampat Regency. The case study taken from the local people of Arborek Village which is a tourism village that has hand-crafed in the form of woven hats and bags of leaf mats. The type of data in this study used qualitative data. The data sources used are primary data and secondary data. The data are collected through by observation, indepth interviews with the some of the interviewees and as well as documentation. The technique of determination of the informant used in this research is purposive sampling. The informants which is selected in this study are representative of the local government in this case the Tourism and Culture officer of Raja Ampat Regency as well as the local community whose doing business craftsmen woven hats and bags. The data are collected is analyzed using the concepts of economic benefits by Leiper. The results of this study found the presence of perceived economic benefit directly by the local communities from tourism sector.

Keywords: Economic Benefit, Local Community, Plating Handcraft, Arborek Village

\section{PENDAHULUAN}

Undang-undang No. 10 Tahun 2009 Tentang Kepariwisataan mengatakan bahwa "Pariwisata merupakan berbagai macam kegiatan wisata dan didukung berbagai fasilitas serta layanan yang disediakan oleh masyarakat, pengusaha, pemerintah, dan pemerintah daerah. Selain itu, kepariwisataan bertujuan untuk meningkatkan pertumbuhan ekonomi, meningkatkan kesejahteraan rakyat, menghapus kemiskinan, mengatasi pengangguran, melestarikan alam, lingkungan, dan sumber daya, memajukan kebudayaan, mengangkat citra bangsa, memupuk rasa cinta tanah air, memperkukuh jati diri dan kesatuan bangsa dan mempererat persahabatan antar bangsa."

Indonesia merupakan negara kepulauan yang telah diakui oleh dunia secara internasional dan telah tercantum dalam naskah UU No. 17 Tahun 1985. Raja Ampat merupakan salah satu kabupaten kepulauan yang berada di bagian barat pulau induk Papua. Raja Ampat memiliki empat pulau besar yaitu Pulau Waigeo, Pulau Salawati, Pulau Misool, dan Pulau Batanta yang terbagi menjadi 24 kecamatan dengan total luas wilayah berdasarkan UU No. 26 tahun 2002 adalah 71.605,69 $\mathrm{km}^{2}$. Raja Ampat memiliki keanekaragaman sumberdaya alam hayati dari masing-masing kepulauannya.

Pariwisata yang berkembang di Raja Ampat saat ini yaitu pariwisata bahari sebagai pariwisata unggulan. Namun selain keindahan bahari, Raja Ampat juga memiliki beberapa kampung (desa) yang ditetapkan oleh pemerintah daerah sebagai desa wisata. Di desa wisata tersebut, wisatawan dapat melihat aktivitas masyarakat lokal di Raja Ampat.

Penelitian ini dilakukan di Kecamatan Meosmansar Kabupaten Raja Ampat dengan fokus lokasi di Kampung Arborek. Berdasarkan pada SK Bupati No.104 tahun 2008, Kec. Meosmansar memiliki lima kampung yang ditetapkan sebagai desa wisata yaitu; Kampung Arborek, Kampung Yenbuba, Kampung Yenwapnor, Kampung Sawinggrai, dan Kampung Saundarek. Kampung Arborek merupakan salah satu kampung wisata percontohan. Kampung Arborek memiliki penghasilan sebagai pengrajin anyaman topi dan tas dari daun tikar. Berdasarkan pada penjelasan singkat di atas, maka akan dibahas mengenai manfaat ekonomi pengrajin anyaman di Kampung Arborek. Rumusan masalah yang akan dibahas yaitu, apakah masyarakat lokal mendapatkan manfaat ekonomi secara langsung dari sektor pariwisata? Tujuan penelitian ini untuk mengetahui manfaat ekonomi secara langsung dari sektor pariwisata bagi masyarakat lokal.

\section{TINJAUAN PUSTAKA}

Tinjauan pustaka dari penelitian ini ada dua, yaitu penelitian sebelumnya yang pertama memiliki lokasi yang sama namun fokus 
penelitian berbeda dan kedua memiliki lokasi berbeda namun fokus penelitian sama. Penelitian sebelumnya yang pertama berjudul "Analisis Keberlanjutan Program Daerah Perlindungan Laut dengan Pendekatan Analytic Hirarchy Process (AHP) di Kabupaten Raja Ampat". Penelitian tersebut memiliki lokasi penelitian yang sama yaitu di Raja Ampat, namun fokus penelitian yang dimiliki berbeda. Penelitian sebelumnya yang kedua berjudul, "Pernyataan Manfaat Ekonomi Makro Berupa PDRB dalam Analisis Ekonomi Pembangunan Jalan Penghubung Bali Utara-Selatan" yang di lakukan oleh Dewa Ketut Sudarsana pada tahun 2011. Penelitian kedua ini memiliki fokus penelitian yang sama yaitu, membahas mengenai manfaat ekonomi, namun lokasi penelitian berbeda.

Landasan konsep yang digunakan dalam penelitian ini yaitu; Konsep Pariwisata, Konsep Manfaat Ekonomi Pariwisata (Leiper dalam Pitana, 2009), dan Konsep Masyarakat Lokal.

\section{METODE PENELITIAN}

Penelitian ini dilakukan di Kampung Arborek, Kecamatan Meosmansar, Kabupaten Raja Ampat, Provinsi Papua Barat. Pengembangan pariwisata di Raja Ampat hampir sebagian besar berada di Kecamatan Meosmansar. Pemilihan Kampung Arborek sebagai lokasi penelitian karena kampung tersebut merupakan salah satu desa wisata. Adapun ruang lingkup penelitian ini meliputi; Manfaat ekonomi yang dirasakan secara langsung oleh masyarakat lokal dari kegiatan pariwisata di Kampung Arborek, dan rata-rata pendapatan masyarakat dari sektor pariwisata. Berdasarkan pada konsep manfaat ekonomi pariwisata yang dikemukakan oleh Leiper (dalam Pitana 2009), terdapat tujuh indikator yaitu: pendapatan dari penukaran valuta asing, menyehatkan neraca perdagangan luar negeri, pendapatan dari usaha atau bisnis pariwisata, pendapatan pemerintah, penyerapan tenaga kerja, Multiplier effects, dan pemanfaatan fasilitas pariwisata oleh masyarakat lokal.

Jenis dan sumber data yang digunakan dalam penelitian ini adalah jenis data kualitatif, sumber data primer dan sekunder (Gunawan. 2013). Teknik pengumpulan data dilakukan dengan observasi, wawancara, dan dokumentasi (studi kepustakaan). Selanjutnya teknik penentuan informan yang digunakan adalah teknik purposive sampling (sampel bertujuan) yaitu penentuan informan dengan pertimbangan tertentu. Informan yang dipilih yaitu para stakeholder pariwisata diantaranya perwakilan dari Dinas Kebudayaan dan Pariwisata Kab. Raja Ampat serta masyarakat lokal pengrajin anyaman. Teknik analisis data menggunakan teknik analisis data selama di lapangan model Miles dan Huberman meliputi reduksi data, penyajian data, dan penarikan kesimpulan dan verifikasi. (Sugiyono. 2014).

\section{HASIL DAN PEMBAHASAN}

5.2. Manfaat Ekonomi Pengrajin Anyaman di Kampung Arborek Kecamatan Meosmansar Kabupaten Raja Ampat

Pariwisata di raja ampat saat ini memiliki perkembangan yang semakin membaik dari awal pemekaran. Berdasarkan pada data dari Dinas Kelautan dan Perikanan Kab. Raja Ampat, didapati jumlah wisatawan selalu meningkat setiap tahun. Jumlah kunjungan wisatawan hampir sebagian besar merupakan wisatawan mancanegara.

Tabel 3.1

Jumlah kunjungan wisatawan di Kabupaten Raja Ampat lima tahun terakhir

\begin{tabular}{|l|l|l|l|}
\hline \multirow{2}{*}{ No. } & \multirow{2}{*}{ Tahun } & \multicolumn{2}{|c|}{$\begin{array}{c}\text { Jumlah kunjungan } \\
\text { wisang) }\end{array}$} \\
\cline { 3 - 4 } & & Asing & \multicolumn{1}{|c|}{ Lokal } \\
\hline 1. & 2011 & 5.159 & 1.246 \\
\hline 2. & 2012 & 5.996 & 1.763 \\
\hline 3. & 2013 & 8.318 & 2.838 \\
\hline 4. & 2014 & 10.247 & 2.691 \\
\hline 5. & 2015 & 11.439 & 2.751 \\
\hline
\end{tabular}

Sumber : Dinas Kelautan dan Perikanan Kab. Raja Ampat (BLUD Unit Pelaksanaan Teknis Dinas Kawasan Konservasi Perairan Daerah)

Kunjungan tersebut secara tidak langsung harus memberikan manfaat ekonomi bagi masyarakat di sekitar daerah destinasi. Kawasan destinasi di Kecamatan Meosmansar hampir sebagian besar merupakan destinasi bawah laut. Sebagian besar wisatawan yang berkunjung adalah untuk menyelam atau snorkeling. Namun hal tersebut tidak menutupi kemungkinan bagi wisatawan untuk 
berkunjung ke desa-desa wisata di kecamatan tersebut.

Dalam penelitian ini, mencoba untuk melihat manfaat ekonomi yang dirasakan secara langsung oleh masyarakat lokal, khususnya di desa wisata Kampung Arborek. Kampung Arborek merupakan salah satu desa wisata dan merupakan kampung swadaya. Selain di teteapkan sebagai desa wisata, kampung tersebut juga memiliki kerajinan khas yang hampir dilakukan oleh semua masyarakat lokal. Berdasarkan pada data BPS Kecamatan Meosmansar, pengrajin di kampung Arborek sebesar $49 \%$ dari keseluruhan masyarakat lokal.

Kerajinan tangan yang dilakukan yaitu anyaman topi (kayafyof) dan tas (kapoen). Uniknya, semua bahan dasar yang dibutuhkan untuk membuat kerajinan tersebut diambil dari luar pulau, karena tidak tersedia bahan pokok di daerah tersebut. Bahan dasar yang digunakan untuk membuat kerajinan anyaman tersebut adalah daun pandan, dan tali rotan. Bahan-bahan tersebut diambil dari Pulau Sop, Pulau Paam, Pulau Gak, dan Pulau Mokoi. Satu gulungan daun tikar yang besar dapat menghasilkan dua anyaman topi dan/atau satu tas sedang, sedangkan untuk tas kecil sebanyak tiga buah. Kerajinan tangan yang dibuat memiliki tingkat kesulitan yang berbeda-beda, hal tersebut yang menjadikan harga satuan kerajinan tergolong mahal. Selain kerajinan anyaman, terdapat juga kerajinan ukiran yang terbuat dari kulit kerang mati sebagai mata kalung. Ukiran kerang mati tersebut memiliki banyak bentuk, sedangkan topi memiliki dua model yaitu model gelombang dan model ikan pari (bau). Tas yang di buat pun memiliki ukuran yaitu tas ukuran sedang dan kecil. Semua kerajinan tersebut memiliki harga yang bervariasi.

Tabel 3.2

Daftar harga kerajinan di Kampung Arborek

\begin{tabular}{|c|c|c|}
\hline \multicolumn{2}{|c|}{ Nama Kerajinan } & $\begin{array}{c}\text { Harga } \\
(\mathrm{Rp})\end{array}$ \\
\hline \multicolumn{2}{|c|}{ Kalung } & 50.000 \\
\hline \multirow{2}{*}{$\begin{array}{c}\text { Tas } \\
\text { Kapoen })\end{array}$} & $\begin{array}{c}\text { Ukuran } \\
\text { kecil }\end{array}$ & 100.000 \\
\cline { 2 - 3 } & $\begin{array}{l}\text { Ukuran } \\
\text { sedang }\end{array}$ & 700.000 \\
\hline Topi & Model & 250.000 \\
\hline
\end{tabular}

\begin{tabular}{|l|c|c|}
\hline (Kayafyof) & gelombang & \\
\cline { 2 - 3 } & $\begin{array}{c}\text { Model ikan } \\
\text { pari }\end{array}$ & 300.000 \\
\hline
\end{tabular}

Sumber : Hasil Penelitian Lapangan 2015

Tabel 3.2 mengelompokkan harga untuk kerajinan tangan yang hendak dijual kepada wisatawan. Kerajinan tersebut selalu dibeli oleh wisatawan yang berkunjung, baik wisatawan mancanegara maupun wisatwan domestik. Namun, sebagaian besar wisatawan yang sering membeli kerajinan anyaman adalah wisatawan mancanegara. Dalam satu bulan, jumlah kerajinan yang dapat terjual berkisar 15 hingga 20 kerajinan tangan dengan harga yang bervariasi.

Tabel 3.3

Daftar rata-rata hasil penjualan kerajinan di Kampung Arborek dalam satu bulan

\begin{tabular}{|c|c|c|c|}
\hline $\begin{array}{c}\text { Nama } \\
\text { kerajinan }\end{array}$ & $\begin{array}{c}\text { Harga } \\
\text { per } \\
\text { Kerajinan } \\
\text { (Rp) }\end{array}$ & $\begin{array}{c}\text { Jumlah } \\
\text { Kerajinan }\end{array}$ & $\begin{array}{c}\text { Total } \\
\text { Harga (Rp) }\end{array}$ \\
\hline Kalung & 50.000 & 10 & 500.000 \\
\hline $\begin{array}{c}\text { Tas Kecil } \\
\text { Tas } \\
\text { sedang }\end{array}$ & 700.000 & 1 & 700.000 \\
\hline $\begin{array}{c}\text { Topi } \\
\text { model } \\
\text { gelombang }\end{array}$ & 250.000 & 5 & 1.250 .000 \\
\hline $\begin{array}{c}\text { Topi } \\
\text { model } \\
\text { ikan pari }\end{array}$ & 300.000 & 4 & 1.200 .000 \\
\hline \multicolumn{2}{|c|}{ Total penghasilan per bulan } & 3.650 .000 \\
\hline \multicolumn{2}{|c|}{ Sumber: Hasil Penelitian Lapangan 2015} \\
\hline
\end{tabular}

Total penghasilan pada tabel 3.3 di atas didapatkan pada bulan-bulan biasa (low season). Sedangkan jika ada event-event seperti ulang tahun kabupaten dan festival, maka penghasilan yang akan didapatkan menjadi dua kali lipat. Data tersebut diperoleh dari informan masyarakat lokal di Kampung Arborek yaitu Regina Sauyai. Setiap bulannya jumlah kerajinan yang terjual bervariasi dan tidak selalu sama.

Berdasarkan pada hasil penelitian di atas, berikut akan dibahas mengenai manfaat ekonomi bagi masyarakat lokal. Jika dianalisis 
menggunakan konsep manfaat ekonomi yang dikemukakan oleh Leiper (dalam Pitana, 2009), maka penjabarannya adalah sebagai berikut.

3.1.1 Pendapatan dari penukaran valuta asing. Dalam penelitian ini penukaran barang dan jasa yang berasal dari masyarakat lokal dan wisatawan berupa kerajinan tangan dari industri rumah tangga yang dikelola oleh masyarakat lokal. Pendapatan dari penjualan kerajinan tangan di Kampung Arborek sebagaian besar dibeli oleh wisatawan mancanegara. Dengan adanya transaksi antara masyarakat lokal dan wisatawan, secara tidak langsung pendapatan dari penukaran valuta asing telah terjadi. Wisatawan akan menukar terlebih dahulu uang yang dibawa dari negaranya dengan satuan uang di Indonesia. Berdasarkan pada data Dinas Kebudayaan dan Pariwisata Kabupaten Raja Ampat, kunjungan wisatawan pada tahun 2014 banyak di kunjungi oleh wisatawan dari USA. Jumlah wisatawan USA sebanyak 1.433 wisatawan. Hal tersebut menjadikan wisatawan harus menukar mata uang yang dimiliki dengan mata uang rupiah dan selanjutnya dapat melakukan transaksi pembelian barang kerajinan yang dikelola masyarakat lokal.

3.1.2 Menyehatkan neraca perdagangan luar negeri. Untuk tingkat kabupaten, Raja Ampat masih belum mampu untuk mengekspor hasil kerajinan tangan masyarakat lokal ke taraf internasional. Hal tersebut dikarenakan Raja Ampat masih baru dalam mengelola sektor pariwisata dan masih memiliki keterbatasan dalam segi teknologi, informasi dan transportasi.

Pendapatan dari usaha atau bisnis pariwisata. Pariwisata Raja Ampat sangat membantu masyarakat lokal dalam segi ekonomi. Khususnya di kampung Arborek, masyarakat lokal sangat terbantu dengan adanya pariwisata. Penjualan kerajinan anyaman yang dibuat oleh masyarakat lokal di kampung tersebut terbilang cukup baik, dikarenakan jumlah penjualan kerajinannya yang sangat laris di pasar wisatawan mancanegara. Hampir sebagian besar wisatawan mancanegara yang berkunjung membeli kerajinan yang dibuat oleh masyarakat lokal. Rincian pendapatan selama satu bulan dapat dilihat pada tabel 3.2 diatas. Rincian pada tabel tersebut mengatakan bahwa total penghasilan kerajinan tangan yang terjual berkisar Rp. 3.650.000,- per bulannya dengan total kerajinan yang terjual berjumlah 20 kerajinan. Berdasarkan pada total penghasilan tersebut, berikut akan dijabarkan pengeluaran selama satu bulan oleh masyarakat lokal.

Tabel 3.4

Daftar Pengeluaran setiap bulan pengrajin

\begin{tabular}{|c|c|c|c|c|}
\hline No & $\begin{array}{c}\text { Jenis } \\
\text { Pengeluaran }\end{array}$ & $\begin{array}{l}\text { Harga } \\
\text { Satuan } \\
\text { (Rp) }\end{array}$ & Jumlah & $\begin{array}{c}\text { Total } \\
\text { pengel } \\
\text { uaran } \\
\text { (Rp) }\end{array}$ \\
\hline 1 & $\begin{array}{c}\text { Gulungan } \\
\text { Tikar }\end{array}$ & 50.000 & 6 gulung & $\begin{array}{c}300.00 \\
0\end{array}$ \\
\hline 2 & Transportasi & $\begin{array}{c}500.000 \\
(P-P)\end{array}$ & & $\begin{array}{c}500.00 \\
0\end{array}$ \\
\hline 3 & $\begin{array}{c}\text { Kebutuhan } \\
\text { bulanan }\end{array}$ & 1.000 .000 & & $\begin{array}{c}1.000 . \\
000\end{array}$ \\
\hline 4 & $\begin{array}{c}\text { Biaya } \\
\text { sekolah } \\
\text { anak di luar } \\
\text { Kampung } \\
\text { Arborek }\end{array}$ & 1.500 .000 & 1 anak & $\begin{array}{c}1.500 . \\
000\end{array}$ \\
\hline \multicolumn{4}{|c|}{ Total Pengeluaran } & $\begin{array}{c}3.300 . \\
000\end{array}$ \\
\hline
\end{tabular}

Sumber; Hasil Penelitian Lapangan 2015

Berdasarkan pada tabel 3.4 tentang rincian pengeluaran diatas, total pengeluaran yang dilakukan oleh para pengrajin sebesar Rp. 3.300.000,- selama satu bulan dan jika dilihat dari hasil penjualan kerajinan maka total uang yang masih ada sejumlah Rp. 350.000,-. Uang sisa tersebut ditabung untuk mengantisipasi biaya tak terduga lainnya. Usaha yang dikelola oleh masyarakat lokal secara individu memiliki pendapatan yang cukup baik untuk mencukupi kehidupan sehari-hari, bahkan sampai menyekolahkan anakanaknya di tingkat perguruan tinggi.

3.1.3 Pendapatan pemerintah. Kontribusi langsung yang didapatkan oleh pihak 
pemerintah adalah hasil penjualan kerajinan dari masyarakat lokal kepada wisatawan. Selain itu, pemerintah mendapat bantuan dari masyarakat lokal untuk membuat kerajinan anyaman saat pemerintah membuat evnt-event besar seperti ulang tahun kabupaten dan festival. Kerajinan anyaman dari masyarakat Arborek sering di tampilkan dalam pameran-pameran budaya dan pariwisata di Raja Ampat.

3.1.4 Penyerapan tenaga kerja. Sektor pariwisata yang berkembang di Raja Ampat sejak tahun 2009 membuka lapangan kerja bagi masyarakat lokal. Khusunya masyarakat lokal yang berperan sebagai pengrajin anyaman di Kampung Wisata Arborek. Dengan adanya sektor pariwisata, kerajinan tangan yang diturunkan dari nenek moyang masyarakat setempat jadi terus berkembang dan menghasilkan uang. Sebelum adanya sektor pariwisata, kerajinan yang dibuat yaitu tas dan topi hanya digunakan oleh masyarakat lokal.

3.1.5 Multiplier effects, selain menyerap tenaga kerja sektor pariwisata juga memberikan manfaat ekonomi bagi masyarakat lokal. Ekonomi masyarakat di Kampung Arborek menjadi lebih baik dengan adanya sektor pariwisata. Selain itu, masyarakat memiliki pekerjaan ganda, selain sebagai pengrajin anyaman topi dan tas, ada sebagian masyarakat lokal yang berprofesi sebagai pemandu wisata. Setiap wisatawan yang berkunjung ke desa wisata tersebut selalu membeli hasil kerajinan yang dibuat oleh masyarakat lokal. Hal tersebut sangat berpengaruh kepada pendapatan masyarakat lokal.

3.1.6 Pemanfaatan fasilitas pariwisata bagi masyarakat lokal. Salah satu fasilitas pariwisata yang dimanfaatkan oleh masyarakat lokal adalah jembatan (dermaga). Dermaga yang dibangun oleh pemerintah untuk mempermudah wisatawan turun dari speedboat juga sering digunakan oleh masyarakat lokal. Selain itu, di Kampung Wisata Arborek terdapat homestay yang di kelolah oleh masyarakat lokal. Homestay tersebut mendapat bantuan dari beberapa relawan baik asing maupun lokal dalam hal mengelola keberlanjutan dari usaha tersebut. Relawan yang ditempatkan di homestay tersebut tidak hanya mengabdi kepada pemilik homestay saja, namun bagi masyarakat lokal di sekitar. Salah satu dari relawan yang berada disana selalu terdapat seorang dokter. Bantuan yang sering di berikan berupa pengajaran bahasa asing bagi anak-anak, dan kesehatan masyarakat lokal.

Berdasarkan pada penjabaran konsep manfaat ekonomi yang dikemukakan oleh Leiper diatas, dapat diakatakan bahwa sektor pariwisata di Kampung Wisata Arborek khususnya dan kawasan Raja Ampat pada umumnya teramati cukup baik. Hal tersebut dilihat dari hampir setiap poin-poin yang dijabarkan memiliki manfaat yang positif.

\section{SIMPULAN DAN SARAN}

\subsection{Simpulan}

Berdasarkan pada penjabaran hasil penelitian diatas dapat disimpulkan bahwa pariwisata Raja Ampat memiliki perkembangan yang cukup baik. Hal tersebut dilihat dari manfaat ekonomi pariwisata yang dirasakan secara langsung oleh masyarakat lokal di Kampung Arborek. Masyarakat lokal merasakan manfaat ekonomi secara langsung dengan terjualnya kerajinan tangan yang dibuat. Survei mengatakan bahwa setiap bulannya kerajinan tangan yang terjual oleh masing-masing individu, masyarakat lokal Kampung Arborek berkisar antara 15 hingga 20 kerajinan tangan dengan variasi harganya masing-masing.

Kerajinan tangan yang dijual oleh masyarakat lokal sangat cukup untuk kehidupannya sehari-hari. Selain itu, hasil dari kerajinan tangan yang dijual pun dapat digunakan untuk membiayai keperluan sekolah anak-anak mereka.

\subsection{Saran}

Berdasarkan pada manfaat dari penelitian ini, akan dijabarkan beberapa saran untuk pihak akademisi, pemerintah daerah, serta masyarakat lokal dalam melihat perkembangan pariwisata Raja Ampat dimasa yang akan datang.

Penelitian ini masih jauh dari kata sempurna. Oleh karena itu disarankan bagi pihak akademisi, agar melakukan penelitian 
lebih lanjut. Dengan lokus yang sama, namun fokus yang diteliti berbeda.

Saran bagi Pemda dalam hal ini Dinas Kebudayaan dan Pariwisata Kabupaten Raja Ampat, untuk lebih kreatif dalam pengembangan pariwisata di Raja Ampat. Hal utama yang harus diperhatikan adalah transportasi dan informasi yang dibutuhkan baik bagi masyarakat lokal maupun wisatawan. Berdasarkan pada penelitian yang dilakukan di Kampung Arborek pada bulan Mei 2015, masih ditemukan beberapa kekurangan dan keluhan yang diajukan baik dari wisatawan maupun masyarakat lokal terkait transportasi dan informasi. Diharapkan dengan berkembangnya pariwisata Raja Ampat saat ini, transportasi untuk masyarakat lokal khususnya dapat dipermudah. Selain itu, membuka peluang akses pasar bagi masyarakat lokal agar bisa mengekspor produk kerajinan.

Saran bagi masyarakat lokal yang berperan dalam pengembangan pariwisata dalam hal ini, para pengrajin anyaman agar menjaga kelestarian budaya yang dimiliki. Anyaman daun 'tikar' yang sudah menjadi warisan dari nenek moyang harus dijaga dan dilestarikan.

\section{Daftar Pustaka:}

BPS Raja Ampat. 2014. Distrik Meosmansar Dalam Angka. Badan Pusat Statistik Kabupaten Raja Ampat. Waisai. Raja Ampat.

BPS Raja Ampat. 2014. Raja Ampat Dalam Angka. Badan Pusat Statistik Kabupaten Raja Ampat. Waisai. Raja Ampat.

Data Wisatawan 2007-2015, Dinas Kebudayaan dan Pariwisata Kabupaten Raja Ampat.

Gunawan, Imam. 2013. Metode Penelitian Kualitatif Teori \& Praktek. Jakarta: Bumi Aksara.

Pitana, I. G. dan Diarta, I. K. S. 2009. Pengantar Ilmu Pariwisata. Yogyakarta: Andi Yogyakarta.

Sugiyono. 2014 (Cetakan ke-6). Metode Penelitian Kombinasi (Mixed Methods). Bandung: Alfabeta.

Undang-undang RI No. 10 Tahun 2009. Tentang Kepariwisataan.

Undang-undang Republik Indonesia Nomor 17 Tahun 1985. Tentang : Pengesahan United Nations Convention On The Law of The Sea (Konvensi Perserikatan Bangsa Bangsa Tentang Hukum Laut).

Undang-undang RI No. 26 Tahun 2002. Tentang Pembentukan Kabupaten Sarmi, Kabupaten Keerom, Kabupaten Sorong Selatan, Kabupaten Raja Ampat, Kabupaten Pegunungan Bintang, Kabupaten Yahukimo, Kabupaten Tolikara, Kabupaten Waropen, Kabupaten Kaimana, Kabupaten Boven Digoel, Kabupaten Mappi, Kabupaten Asmat, Kabupaten Teluk Bintuni, dan Kabupaten Teluk Wondama di Provinsi Papua. 